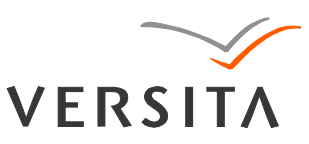

GEOCHRONOMETRIA 40(4) 2013: 229-238

DOI 10.2478/s13386-013-0128-3

Available online at

www.springerlink.com

\title{
RESIDUAL DOSES AND SENSITIVITY CHANGE OF POST IR IRSL SIGNALS FROM POTASSIUM FELDSPAR UNDER DIFFERENT BLEACHING CONDITIONS
}

\author{
YIWEI CHEN ${ }^{1}$, SHENG-HUA LI ${ }^{1}$ and BO LI $^{2}$ \\ ${ }^{I}$ Department of Earth Sciences, The University of Hong Kong, Pokfulam Road, Hong Kong, China \\ ${ }^{2}$ Centre for Archaeological Science, School of Earth and Environmental Sciences, University of Wollongong, \\ Wollongong, NSW 2522, Australia
}

Received 29 January 2013

Accepted 21 August 2013

\begin{abstract}
The residual doses and sensitivity change for potassium-rich feldspar (K-feldspar) have been studied using the post-infrared infrared stimulated luminescence (pIRIR) and multi-elevatedtemperature post-IR IRSL (MET-pIRIR) protocols. Laboratory simulated poorly-bleached and wellbleached samples were those K-feldspar grains bleached using a solar simulator for 10 minutes and 8 hours, respectively. The residual doses rise with stimulation temperature and time. The poorlybleached sample has larger residual doses than the well-bleached sample, especially at high stimulation temperatures. The high-temperature pIRIR signals contain a large amount of hard-to-bleach signals. A decrease of luminescence sensitivity was observed after conducting a high-temperaturetreatment in the measurement cycles. The sensitivity decreases significantly between the first and the second cycle. The extent of decrease in sensitivity shows a clear temperature trend. The higher the stimulation temperature of pIRIR signals is, the larger the sensitivity decreases. This decrease is more severe for the poorly-bleached sample than for the well-bleached sample, and could possibly lead to problems in sensitivity correction.
\end{abstract}

Keywords: residual doses, sensitivity change, infrared stimulated luminescence, K-feldspar.

\section{INTRODUCTION}

Optically stimulated luminescence (OSL) dating technique has undergone extensive development since the single-aliquot regenerative-dose (SAR) protocol was proposed (Murray and Wintle, 2000; Wintle and Murray, 2006). In the SAR protocol, sensitivity changes caused by laboratory measurements of quartz OSL signals have been successfully monitored and corrected for by measuring the test dose-induced luminescence. The SAR protocol has also been applied to infrared stimulated lumines-

Corresponding author: S.-H. Li

e-mail: shli@hku.hk cence (IRSL) signals from feldspar (Wallinga et al., 2000). However, the anomalous fading of IRSL signals from feldspar has long been the major difficulty that hindered its usage for dating of sediments (Wintle, 1973; Spooner, 1994; Huntley and Lamothe, 2001).

It has been reported that following a low-temperature $\left(50^{\circ} \mathrm{C}\right)$ IRSL measurement, post-IR IRSL signals (pIRIR) measured at elevated temperatures $\left(>200^{\circ} \mathrm{C}\right)$ has a lower fading rate compared to conventional IRSL (Thomsen et al., 2008). This has led to the development of the twostep post-IR IRSL protocol (Buylaert et al., 2009; Thiel et al., 2011). Meanwhile, Li and Li (2011) reported a multi-elevated-temperature post-IR IRSL (MET-pIRIR) 
protocol in which the non-fading component from $\mathrm{K}$ feldspar pIRIR signals can be identified by measuring pIRIR at progressively increased stimulation temperatures (from 50 to $250^{\circ} \mathrm{C}$ ). Some tests based on the METpIRIR were also reported using typical aeolian sediment from Loess Plateau and deserts in northern China (e.g. Fu et al., 2012; $\mathrm{Li}$ and $\mathrm{Li}, 2012 \mathrm{~b}$ ).

In these SAR procedures, the reliability of sensitivity correction for these pIRIR signals is the basis for accurate $\mathrm{D}_{\mathrm{e}}$ measurements. Previous studies mainly focus on wellbleached sediments, e.g. aeolian loess and desert dune sand. The performance of these protocols for poorlybleached samples is relatively not well explored, with special regards to sensitivity changes for pIRIR signals from K-feldspar when high-temperature-treatment is adopted. For bleachability of high-temperature pIRIR signals, $\mathrm{Li}$ and $\mathrm{Li}$ (2011) measured residual doses of high-temperature pIRIR signals for typical aeolian sediments, and reported a dose of a few Gy. Buylaert et al. (2012) suggested the high-temperature pIRIR signals have slower bleaching rates under daylight conditions that could cause high residual doses, which may lead to overestimated $D_{e}$ values for young samples. Some recent studies have successfully tested the performance of SAR pIRIR protocols using small aliquots and single grain technique on young coastal sediments (Reimann et al., 2011, 2012). Using single grain analysis of a natural poorly-bleached sample, Reimann et al. (2012) could effectively overcome age overestimation, which are caused by averaging effects in multiple-grain singlealiquot measurements. Studies on the bleachability of pIRIR signals at elevated temperature are remaining to be further studied for various samples to estimate the residual doses.

In this study, we aim to measure the residual doses and the bleachability of pIRIR signals stimulated at various temperatures by using laboratory simulated well- and poorly- bleached K-feldspar samples and by applying the pIRIR and MET-pIRIR protocols. The performance of the SAR sensitivity correction was investigated. Sensitivity changes as function of measurement cycles in these protocols were also investigated to test the effectiveness of the sensitivity correction.

\section{SAMPLES AND EXPERIMENTAL DETAILS}

A Holocene lakeshore sandy sediment sample from Tibet was prepared using routine procedures, under subdued red light condition (Aitken, 1998). It was firstly treated with $10 \% \mathrm{HCl}$ acid and $20 \% \mathrm{H}_{2} \mathrm{O}_{2}$ solution to remove carbonates and organic materials, respectively. After conducting dry sieving, K-feldspar grains $(125-150 \mu \mathrm{m})$ were separated using sodium polytungstate heavy liquid with densities smaller than $2.58 \mathrm{~g} / \mathrm{cm}^{3}$. The separated $\mathrm{K}$ feldspar grains were etched with $10 \% \mathrm{HF}$ acid for $40 \mathrm{~min}$ to remove the outer surface. The K-feldspar grains were dried and mounted on 10-mm-diameter aluminium discs for measurement, using silicone oil as an adhesive. In our experiments, the samples were prepared as medium size aliquots (containing hundreds of grains). An automated Risø TL-DA-20 reader was used for IRSL measurements in the Luminescence Dating Laboratory of The University of Hong Kong. It is equipped with IR diodes $(870 \pm 40 \mathrm{~nm})$ for stimulation with a power of $\sim 135 \mathrm{~mW} / \mathrm{cm}^{2}$ at sample position (Bøtter-Jensen et al., 2000). A ${ }^{90} \mathrm{Sr} /{ }^{90} \mathrm{Y}$ beta source was attached to the reader for irradiation with a dose rate of $0.126 \mathrm{~Gy} / \mathrm{s}$ calibrated on aluminium discs. IRSL signals were detected through a combination of Schott BG-39 and Corning 7-59 filters with the transmission in the range of $320-480 \mathrm{~nm}$.

To simulate poorly-bleached and well-bleached samples, the K-feldspar grains were firstly bleached by an Oriel solar simulator (model: 68820) for 4 hours to reset the natural signal. They were then given a beta dose of 500 Gy. After that, well-bleached and poorly-bleached samples were prepared as:

1) Well-bleached sample (WB): this sample was bleached under the solar simulator for 8 hours.

2) Poorly-bleached sample (PB): this sample was bleached by solar simulator for only 10 minutes. It should be noted that PB in this study is homogeneously poorly bleached, while in nature poorlybleached samples mostly refer to heterogeneously poorly bleached.

\section{MEASURING RESIDUAL DOSES}

To evaluate the bleachability for pIRIR signals that stimulated at various temperatures, the residual doses for pIRIR signals were measured using the MET-pIRIR (50, $\left.100,150,200,250,300^{\circ} \mathrm{C}\right)(\mathrm{Li}$ and $\mathrm{Li}, 2012 \mathrm{~b})$, pIRIR $\left(50,225^{\circ} \mathrm{C}\right)$, pIRIR $\left(50,290^{\circ} \mathrm{C}\right)$ and pIRIR $\left(200,290^{\circ} \mathrm{C}\right)$ protocols (Buylaert et al., 2009; Thiel et al., 2011; Li and $\mathrm{Li}, 2012 \mathrm{a})$. The details of these protocols are shown in Table 1.

The residual doses of the two-step pIRIR protocols range from 2.2 to 29.0 Gy for $\mathrm{PB}, 0.6$ to 7.2 Gy for WB; while the results for MET-pIRIR range from 7.7 to 49.0 Gy for PB and 4.1 to 20.4 Gy for WB (Table 2). Results have also been reported that a variety of residual doses up to $\sim 55$ Gy were found in high-temperature pIRIR signals from typical aeolian sediments from Eurasia (Li et al., 2013a). The residual doses found in our study are large, even after $8 \mathrm{~h}$ solar simulator bleaching. A significantly smaller residual dose (less than $1 \mathrm{~Gy}$ ) has been reported for well-bleached sample after prolonged bleaching in a solar simulator (Reimann et al., 2012) and for a modern natural sample (Madsen et al., 2011), using the pIRIR 180 and $150^{\circ} \mathrm{C}$ signals, respectively. Under different bleaching conditions including solar simulator, daylight and infrared light source, a similar small residual dose is reported for the well-bleached sample and a dose of 1-3.5 Gy for the poorly-bleached sample (after $10 \mathrm{~min}$ IR bleaching) using the pIRIR $150^{\circ} \mathrm{C}$ signal (Reimann 
Table 1. Residual doses of well- and poorly- bleached samples (WB and PB), measured with SAR protocol (Buylaert et al., 2009; Thiel et al., 2011; Li and Li, 2012a, 2012b).

\begin{tabular}{|c|c|c|c|c|}
\hline Step & MET-pIRIR $\left(50,100,150,200,250,300^{\circ} \mathrm{C}\right)$ & $\operatorname{pIRIR}\left(50,225^{\circ} \mathrm{C}\right)$ & $\operatorname{pIRIR}\left(50,290^{\circ} \mathrm{C}\right)$ & pIRIR $\left(200,290^{\circ} \mathrm{C}\right)$ \\
\hline 1 & Dose, $D_{i}{ }^{a}$ & Dose, $D_{i}{ }^{a}$ & Dose, $D_{i}{ }^{a}$ & Dose, $D_{i}$ a \\
\hline 2 & Preheat at $320^{\circ} \mathrm{C}, 60 \mathrm{~s}$ & Preheat at $250^{\circ} \mathrm{C}, 60 \mathrm{~s}$ & Preheat at $320^{\circ} \mathrm{C}, 60 \mathrm{~s}$ & Preheat at $320^{\circ} \mathrm{C}, 60 \mathrm{~s}$ \\
\hline 3 & IRSL $100 \mathrm{~s}$ at $50^{\circ} \mathrm{C}\left(\mathrm{L}_{\mathrm{x}}\right)$ & IRSL $100 \mathrm{~s}$ at $50^{\circ} \mathrm{C}\left(\mathrm{L}_{\mathrm{x}}\right)$ & IRSL $200 \mathrm{~s}$ at $50^{\circ} \mathrm{C}\left(\mathrm{L}_{\mathrm{x}}\right)$ & IRSL $200 \mathrm{~s}$ at $200^{\circ} \mathrm{C}\left(\mathrm{L}_{\mathrm{x}}\right)$ \\
\hline 4 & IRSL $100 \mathrm{~s}$ at $100^{\circ} \mathrm{C}\left(\mathrm{L}_{\mathrm{x}}\right)$ & IRSL $100 \mathrm{~s}$ at $225^{\circ} \mathrm{C}\left(\mathrm{L}_{\mathrm{x}}\right)$ & IRSL $200 \mathrm{~s}$ at $290^{\circ} \mathrm{C}\left(\mathrm{L}_{\mathrm{x}}\right)$ & IRSL $200 \mathrm{~s}$ at $290^{\circ} \mathrm{C}\left(\mathrm{L}_{\mathrm{x}}\right)$ \\
\hline 5 & IRSL $100 \mathrm{~s}$ at $150^{\circ} \mathrm{C}\left(\mathrm{L}_{\mathrm{x}}\right)$ & Test dose, $D_{t}$ & Test dose, $D_{t}$ & Test dose, $D_{t}$ \\
\hline 6 & IRSL $100 \mathrm{~s}$ at $200^{\circ} \mathrm{C}\left(\mathrm{L}_{\mathrm{x}}\right)$ & Preheat at $250^{\circ} \mathrm{C}, 60 \mathrm{~s}$ & Preheat at $320^{\circ} \mathrm{C}, 60 \mathrm{~s}$ & Preheat at $320^{\circ} \mathrm{C}, 60 \mathrm{~s}$ \\
\hline 7 & IRSL $100 \mathrm{~s}$ at $250^{\circ} \mathrm{C}\left(\mathrm{Lx}_{\mathrm{x}}\right)$ & IRSL $100 \mathrm{~s}$ at $50^{\circ} \mathrm{C}\left(\mathrm{T}_{\mathrm{x}}\right)$ & IRSL $200 \mathrm{~s}$ at $50^{\circ} \mathrm{C}\left(\mathrm{T}_{\mathrm{x}}\right)$ & IRSL $200 \mathrm{~s}$ at $200^{\circ} \mathrm{C}\left(\mathrm{T}_{\mathrm{x}}\right)$ \\
\hline 8 & IRSL $100 \mathrm{~s}$ at $300^{\circ} \mathrm{C}\left(\mathrm{Lx}_{\mathrm{x}}\right)$ & IRSL $100 \mathrm{~s}$ at $225^{\circ} \mathrm{C}\left(\mathrm{T}_{\mathrm{x}}\right)$ & IRSL $200 \mathrm{~s}$ at $290^{\circ} \mathrm{C}\left(\mathrm{T}_{\mathrm{x}}\right)$ & IRSL $200 \mathrm{~s}$ at $290^{\circ} \mathrm{C}\left(\mathrm{T}_{\mathrm{x}}\right)$ \\
\hline 9 & Test dose, $D_{t}$ & IRSL 40 s at $290^{\circ} \mathrm{C}$ & IRSL $100 \mathrm{~s}$ at $325^{\circ} \mathrm{C}$ & IRSL $40 \mathrm{~s}$ at $325^{\circ} \mathrm{C}$ \\
\hline 10 & Preheat at $320^{\circ} \mathrm{C}, 60 \mathrm{~s}$ & Return to step 1 & Return to step 1 & Return to step 1 \\
\hline 11 & IRSL $100 \mathrm{~s}$ at $50^{\circ} \mathrm{C}\left(T_{x}\right)$ & & & \\
\hline 12 & IRSL $100 \mathrm{~s}$ at $100^{\circ} \mathrm{C}\left(\mathrm{T}_{\mathrm{x}}\right)$ & & & \\
\hline 13 & IRSL $100 \mathrm{~s}$ at $150^{\circ} \mathrm{C}\left(\mathrm{T}_{\mathrm{x}}\right)$ & & & \\
\hline 14 & IRSL $100 \mathrm{~s}$ at $200^{\circ} \mathrm{C}\left(\mathrm{T}_{\mathrm{x}}\right)$ & & & \\
\hline 15 & IRSL $100 \mathrm{~s}$ at $250^{\circ} \mathrm{C}\left(\mathrm{T}_{\mathrm{x}}\right)$ & & & \\
\hline 16 & IRSL $100 \mathrm{~s}$ at $300^{\circ} \mathrm{C}\left(\mathrm{T}_{\mathrm{x}}\right)$ & & & \\
\hline 17 & IRSL $100 \mathrm{~s}$ at $325^{\circ} \mathrm{C}$ & & & \\
\hline 18 & Return to step 1 & & & \\
\hline
\end{tabular}

Table 2. Residual doses for the MET-pIRIR protocol (50, 100, 150, $\left.200,250,300^{\circ} \mathrm{C}\right)$ and pIR-IRSL protocol of $\left(50,225^{\circ} \mathrm{C}\right),\left(50,290^{\circ} \mathrm{C}\right)$ and $\left(200,290^{\circ} \mathrm{C}\right)$.

\begin{tabular}{ccc}
\hline $\begin{array}{c}\text { Temperature } \\
\left({ }^{\circ} \mathbf{C}\right)\end{array}$ & $\begin{array}{c}\text { Residual dose for } \\
\text { PB (Gy) }\end{array}$ & $\begin{array}{c}\text { Residual dose for } \\
\text { WB }(G y)\end{array}$ \\
\hline 50 & 7.7 & 4.1 \\
100 & 21.9 & 11.6 \\
150 & 27.4 & 12.8 \\
200 & 30.9 & 13.5 \\
250 & 34.4 & 15.0 \\
300 & 49.0 & 20.4 \\
& 2.2 & 0.6 \\
50 & 15.2 & 5.4 \\
225 & 7.8 & 2.4 \\
& 27.6 & 6.6 \\
50 & 20.5 & 5.5 \\
290 & 29.0 & 7.2 \\
\hline
\end{tabular}

Note: the residual dose is obtained using data in the first 4 second for integration. The total stimulation time is $100 \mathrm{~s}$. The residual doses are the average from three aliquots.

and Tsukamoto, 2012). Using the pIRIR $(50,290)$ protocol, Buylaert et al. (2012) reported a linear relationship between residual doses of the pIRIR $290^{\circ} \mathrm{C}$ signal and burial dose for a set of samples having different burial doses, after 4 hour bleaching under a solar simulator. They suggest an unbleachable residual dose of $\sim 4$ Gy. After bleaching a sample for 4 hour in a solar simulator, a comparable residual dose of $\sim 7$ Gy has been reported for the pIRIR $290^{\circ} \mathrm{C}$ signal (Reimann et al., 2011). These results suggest that the residual doses for different pIRIR signals from various samples could vary significantly.

Fig. 1 shows the residual doses for the MET-pIRIR $\left(50,100,150,200,250,300^{\circ} \mathrm{C}\right)$ protocol, with the lower series for $\mathrm{WB}$ and the higher series for $\mathrm{PB}$, respectively. The residual doses at each stimulation temperature are plotted against the stimulation time. $\mathrm{D}_{\mathrm{e}}$ values were calculated at successive intervals of $2 \mathrm{~s}$. Each point is the average from three aliquots. Only the residual doses of the first $20 \mathrm{~s}$ were plotted. The total stimulation time is $100 \mathrm{~s}$. It is observed that $\mathrm{PB}$ has higher residual doses than WB. The difference between residual doses for PB and WB increases with stimulation temperature. Hightemperature pIRIR signals are relatively hard-to-bleach and contain larger residuals. A modified-low-temperature MET-pIRIR protocol has been suggested to avoid large residuals using the stimulation temperatures of 110,140 and $170^{\circ} \mathrm{C}$ ( $\mathrm{Fu}$ and $\left.\mathrm{Li}, 2013\right)$. It is also reported for the two-step pIRIR protocols that lowering temperature for preheat and the second IR stimulation can reduce the residual doses (e.g. Madsen et al., 2011; Reimann et al., 2011). It is noted in Fig. 1 that an abrupt rise of residual dose from 250 to $300^{\circ} \mathrm{C}$ is observed for both WB and PB, implying that the luminescence characteristics may have a significant change during this temperature interval.

It is also observed that the residual doses of lowtemperature pIRIR signals show a rise with stimulation time in $\mathrm{D}_{\mathrm{e}}$-t plot (Fig. 1), indicating that the initial part of signals relate more to easy-to-bleach signals; while the later part relates more to hard-to-bleach signals $(\mathrm{Li}$ and Wintle, 1992). For PB, this increment in residual doses is much smaller for $100^{\circ} \mathrm{C}$ stimulation than $50^{\circ} \mathrm{C}$, implying that the proportion for easy-to-bleach signals for $100^{\circ} \mathrm{C}$ stimulation decreases significantly compared to that of 


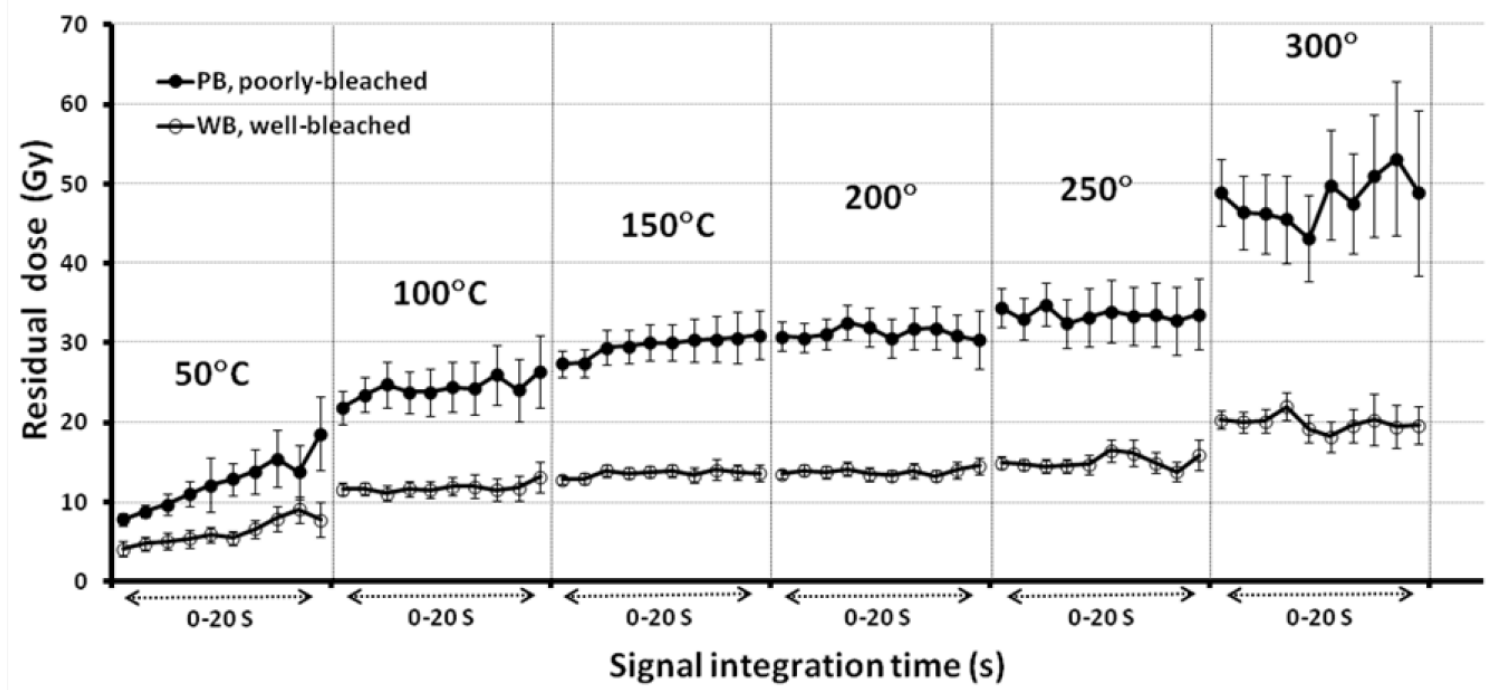

Fig. 1. Residual dose for well-bleached sample (WB, the lower series) and poorly-bleached sample (PB, the upper series) changes with the stimulation time and temperatures, from pIRIR signals that were stimulated at various temperatures, using MET-pIRIR protocol of (50, 100, 150, 200, 250, $\left.300^{\circ} \mathrm{C}\right)(\mathrm{Li}$ and $\mathrm{Li}, 2012 \mathrm{~b})$. De values were calculated at successive intervals of 2 second. Only the residual doses of first $20 \mathrm{~s}$ were plotted. The total stimulation time is $100 \mathrm{~s}$. Each point is the average from three aliquots, so as results below. The details of MET-pIRIR protocol (50, 100, 150, 200, $250,300^{\circ} \mathrm{C}$ ) are shown in Table 1.

the $50^{\circ} \mathrm{C}$ signals. The residual dose gradually reaches a plateau at $150^{\circ} \mathrm{C}$ or higher, implying that after this temperature luminescence associated with hard-to-bleach signals dominates the total signal. For WB, similar pattern is observed but the increment in residual doses is much smaller in the $50^{\circ} \mathrm{C}$ signals. The $\mathrm{D}_{\mathrm{e}}$-t plateau occurs at a relatively low temperature $\left(100^{\circ} \mathrm{C}\right)$. PB shows larger increment of residual doses with stimulation time, especially for low-temperature signals. This suggests that major part of residual low-temperature pIRIR signal for $\mathrm{PB}$ is from the easy-to-bleach signals. These easy-tobleach signals remain large in $\mathrm{PB}$, but can be bleached under prolonged solar bleaching in $\mathrm{WB}$, because $\mathrm{WB}$ shows smaller increment of residual doses with stimulation time.

Fig. 2 shows the residual doses for pIRIR protocols of $\left(50,225^{\circ} \mathrm{C}\right),\left(50,290^{\circ} \mathrm{C}\right)$ and $\left(200,290^{\circ} \mathrm{C}\right)$, for both $\mathrm{PB}$ (upper series) and WB (lower series). Each point is the average from three aliquots. Similar patterns to the METpIRIR results can be observed for the two-step pIRIR protocols. PB has larger residual doses than WB. A rise in $D_{\mathrm{e}}$-t plot is found for low-temperature IRSL signals while high-temperature pIRIR shows a negligible $D_{\mathrm{e}}-\mathrm{t}$ increment. It is noted that in the pIRIR protocol $(50$, $290^{\circ} \mathrm{C}$ ), the $290^{\circ} \mathrm{C}$-pIRIR also shows an increasing $\mathrm{D}_{\mathrm{e}}-\mathrm{t}$ (PB in Fig. 2b). This suggests that after the first step IRSL $\left(50^{\circ} \mathrm{C}\right)$, easy-to-bleach signals are still present in the following $290^{\circ} \mathrm{C}$ pIRIR signals. However, in the pIRIR protocols of $\left(50,225^{\circ} \mathrm{C}\right)$ and $\left(200,290^{\circ} \mathrm{C}\right)$, a smaller increment of $\mathrm{D}_{\mathrm{e}}-\mathrm{t}$ for high-temperature pIRIR signals is observed. This different trend of $\mathrm{D}_{\mathrm{e}}$-t for hightemperature pIRIR signals implies that the bleaching rate of pIRIR signals of different stimulation temperatures varies significantly. Different combination of the prior-IR and post-IR stimulation temperatures can result in different proportions between the easy-to-bleach and hard-tobleach components. Therefore, different residual doses are expected.

\section{MEASURING SENSITIVITY CHANGES}

In order to study the sensitivity changes of the pIRIR signals as function of measurement cycles, aliquots of WB and PB were given a fixed dose of 25 Gy as regenerative dose $\left(\mathrm{L}_{\mathrm{x}}\right)$ and a test dose of 6.3 Gy was given prior to the $T_{x}$ measurement, repeated for four to six cycles, using different pIRIR protocols: MET-pIRIR protocol with IR stimulation temperatures of 50,100, 150, 200, $250^{\circ} \mathrm{C}(\mathrm{Li}$ and $\mathrm{Li}, 2011)$ and a simplified MET-pIRIR protocol with IR stimulation temperature at 110, 140 and $170^{\circ} \mathrm{C}(\mathrm{Fu}$ and $\mathrm{Li}, 2013)$, and two-step pIRIR protocols (pIRIR $\left(50,225^{\circ} \mathrm{C}\right)$ and pIRIR $\left(50,290^{\circ} \mathrm{C}\right)$ ) (Buylaert et al. 2009; Thiel et al., 2011). The details of these protocols are shown in Table 3. Six aliquots of WB and PB were used for each experiment. Three of the six aliquots were exposed to a hot bleach (high-temperature IRSL stimulation, Table 3) after each $T_{x}$ measurement at the end of each SAR cycle. The other three aliquots were not exposed to a hot bleach. 
Table 3. Sensitivity change as function of measurement cycles, measured with SAR protocols (Buylaert et al., 2009; Thiel et al., 2011; Li and Li, 2011; Fu and Li, 2013).

\begin{tabular}{|c|c|c|c|c|}
\hline Step & MET-pIRIR $\left(110,140,170^{\circ} \mathrm{C}\right)$ & MET-pIRIR $\left(50,100,150,200,250^{\circ} \mathrm{C}\right)$ & pIRIR $\left(50,225^{\circ} \mathrm{C}\right)$ & $\operatorname{pIRIR}\left(50,290^{\circ} \mathrm{C}\right)$ \\
\hline 1 & Dose, 25 Gy & Dose, $25 \mathrm{~Gy}$ & Dose, 25 Gy & Dose, 25 Gy \\
\hline 2 & Preheat at $200^{\circ} \mathrm{C}, 60 \mathrm{~s}$ & Preheat at $300^{\circ} \mathrm{C}, 10 \mathrm{~s}$ & Preheat at $250^{\circ} \mathrm{C}, 60 \mathrm{~s}$ & Preheat at $320^{\circ} \mathrm{C}, 60 \mathrm{~s}$ \\
\hline 3 & IRSL $100 \mathrm{~s}$ at $110^{\circ} \mathrm{C}\left(\mathrm{L}_{\mathrm{x}}\right)$ & IRSL $100 \mathrm{~s}$ at $50^{\circ} \mathrm{C}\left(\mathrm{L}_{\mathrm{x}}\right)$ & IRSL $100 \mathrm{~s}$ at $50^{\circ} \mathrm{C}\left(\mathrm{L}_{\mathrm{x}}\right)$ & IRSL $200 \mathrm{~s}$ at $50^{\circ} \mathrm{C}\left(\mathrm{L}_{\mathrm{x}}\right)$ \\
\hline 4 & IRSL $100 \mathrm{~s}$ at $140^{\circ} \mathrm{C}\left(\mathrm{L}_{x}\right)$ & IRSL $100 \mathrm{~s}$ at $100^{\circ} \mathrm{C}\left(\mathrm{L}_{\mathrm{x}}\right)$ & IRSL $100 \mathrm{~s}$ at $225^{\circ} \mathrm{C}\left(\mathrm{L}_{\mathrm{x}}\right)$ & IRSL $200 \mathrm{~s}$ at $290^{\circ} \mathrm{C}\left(\mathrm{L}_{\mathrm{x}}\right)$ \\
\hline 5 & IRSL $100 \mathrm{~s}$ at $170^{\circ} \mathrm{C}\left(\mathrm{L}_{\mathrm{x}}\right)$ & IRSL $100 \mathrm{~s}$ at $150^{\circ} \mathrm{C}\left(\mathrm{L}_{x}\right)$ & Test dose, $6.3 \mathrm{~Gy}$ & Test dose, $6.3 \mathrm{~Gy}$ \\
\hline 6 & Test dose, $6.3 \mathrm{~Gy}$ & IRSL $100 \mathrm{~s}$ at $200^{\circ} \mathrm{C}\left(\mathrm{L}_{x}\right)$ & Preheat at $250^{\circ} \mathrm{C}, 60 \mathrm{~s}$ & Preheat at $320^{\circ} \mathrm{C}, 60 \mathrm{~s}$ \\
\hline 7 & Preheat at $200^{\circ} \mathrm{C}, 60 \mathrm{~s}$ & IRSL $100 \mathrm{~s}$ at $250^{\circ} \mathrm{C}\left(\mathrm{Lx}^{\prime}\right)$ & IRSL $100 \mathrm{~s}$ at $50^{\circ} \mathrm{C}\left(\mathrm{T}_{x}\right)$ & IRSL $200 \mathrm{~s}$ at $50^{\circ} \mathrm{C}\left(\mathrm{L} x_{\mathrm{x}}\right)$ \\
\hline 8 & IRSL $100 \mathrm{~s}$ at $110^{\circ} \mathrm{C}\left(\mathrm{T}_{\mathrm{x}}\right)$ & Test dose, $6.3 \mathrm{~Gy}$ & IRSL $100 \mathrm{~s}$ at $225^{\circ} \mathrm{C}\left(\mathrm{T}_{\mathrm{x}}^{\prime}\right)$ & IRSL $200 \mathrm{~s}$ at $290^{\circ} \mathrm{C}\left(\mathrm{L}_{\mathrm{x}}\right)$ \\
\hline 9 & IRSL $100 \mathrm{~s}$ at $140^{\circ} \mathrm{C}\left(\mathrm{T}_{\mathrm{x}}\right)$ & Preheat at $300^{\circ} \mathrm{C}, 10 \mathrm{~s}$ & IRSL 40 s at $290^{\circ} \mathrm{C}$ & IRSL $100 \mathrm{~s}$ at $325^{\circ} \mathrm{C}$ \\
\hline 10 & IRSL $100 \mathrm{~s}$ at $170^{\circ} \mathrm{C}\left(\mathrm{T}_{\mathrm{x}}\right)$ & IRSL $100 \mathrm{~s}$ at $50^{\circ} \mathrm{C}\left(\mathrm{T}_{\mathrm{x}}\right)$ & Return to step 1 & Return to step 1 \\
\hline 11 & IRSL $100 \mathrm{~s}$ at $280^{\circ} \mathrm{C}$ & IRSL $100 \mathrm{~s}$ at $100^{\circ} \mathrm{C}\left(\mathrm{T}_{\mathrm{x}}^{\prime}\right)$ & & \\
\hline 12 & Return to step 1 & IRSL $100 \mathrm{~s}$ at $150^{\circ} \mathrm{C}\left(\mathrm{T}_{\mathrm{x}}\right)$ & & \\
\hline 13 & & IRSL $100 \mathrm{~s}$ at $200^{\circ} \mathrm{C}\left(\mathrm{T}_{\mathrm{x}}\right)$ & & \\
\hline 14 & & IRSL $100 \mathrm{~s}$ at $250^{\circ} \mathrm{C}\left(\mathrm{T}_{\mathrm{x}}\right)$ & & \\
\hline 15 & & IRSL $100 \mathrm{~s}$ at $320^{\circ} \mathrm{C}$ & & \\
\hline 18 & & Return to step 1 & & \\
\hline
\end{tabular}

Note: the sensitivity change is measured with a fixed regenerative dose of $25 \mathrm{~Gy}$ and test dose of $6.3 \mathrm{~Gy}$, repeated for 4 to 6 times for both WB and PB.
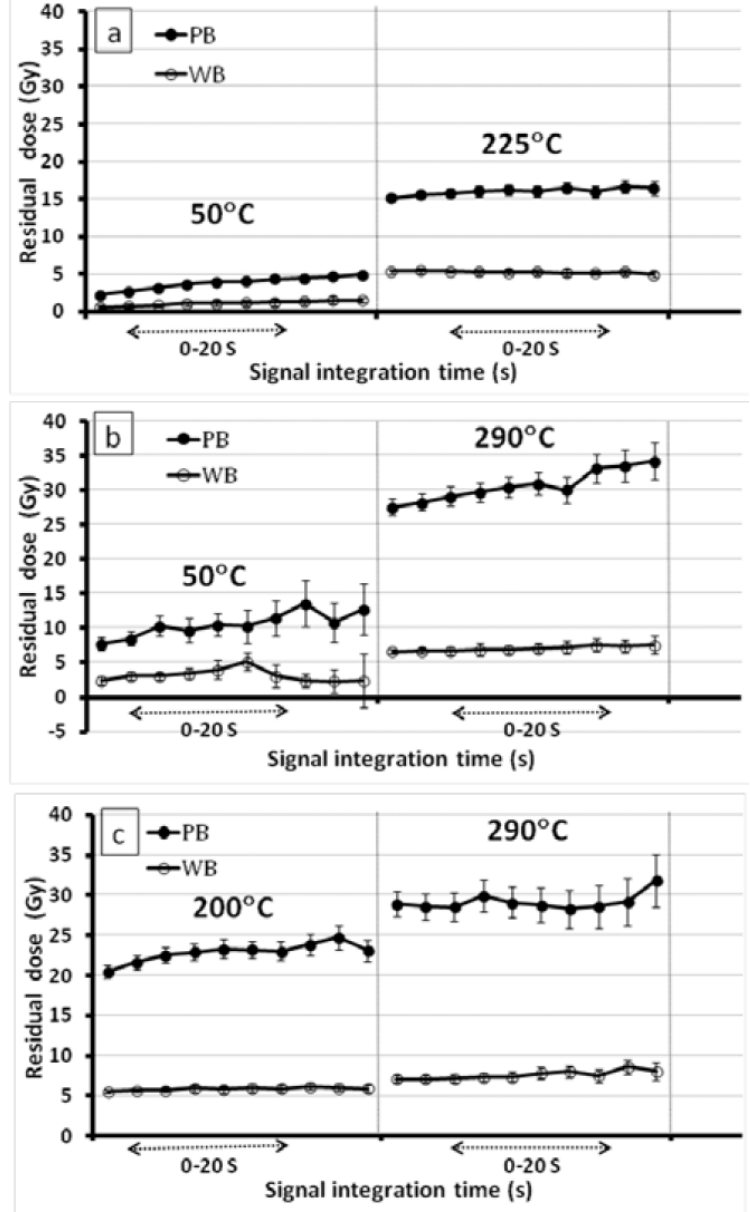

Fig. 2. Residual dose for the pIR-IRSL protocols of WB and $P B$ for: a) $50,225^{\circ} \mathrm{C}$ (Buylaert et al., 2009); b) 50, $290^{\circ} \mathrm{C}$ (Thiel et al., 2011); c) $200,290^{\circ} \mathrm{C}$ ( $\mathrm{Li}$ and $\mathrm{Li}, 2012 \mathrm{a}$ ). The legend and integration of signals is same to that of Fig. 1 with the measuring method changed to two-step pIRIR protocols. The details of pIRIR protocols are shown in Table 1.

\section{Sensitivity change in the MET-pIRIR protocol}

\section{MET-pIRIR protocol $\left(110,140,170^{\circ} \mathrm{C}\right)$}

The MET-pIRIR protocol $\left(110,140\right.$ and $\left.170^{\circ} \mathrm{C}\right)(\mathrm{Fu}$ and $\mathrm{Li}, 2013$ ) was repeated for 6 cycles for $\mathrm{WB}$ and $\mathrm{PB}$. Fig. 3 shows the normalized $L_{x}$ (bold line, left scale), $T_{x}$ (dashed line, left scale) and $\mathrm{L}_{\mathrm{x}} / \mathrm{T}_{\mathrm{x}}$ (scattered data points in lower part of figure, right scale) as a function of measurement cycles at 110 (blue), 140 (green) and $170^{\circ} \mathrm{C}$ (red). Figs. 3a and b show the results for PB and WB, respectively, without a hot bleach. Figs. $3 \mathbf{c}$ and $\mathbf{d}$ show the results for $\mathrm{PB}$ and $\mathrm{WB}$ with a hot bleach (IRSL $280^{\circ} \mathrm{C}, 100 \mathrm{~s}$ ) at the end of each cycle.

For $\mathrm{PB}$, the $\mathrm{L}_{\mathrm{x}} 110^{\circ} \mathrm{C}$ (blue bold line) rises with cycle number (Fig. 3a). $\mathrm{L}_{\mathrm{x}} 140^{\circ} \mathrm{C}$ (green bold) and $\mathrm{L}_{\mathrm{x}} 170^{\circ} \mathrm{C}$ (red bold) decrease from the first cycle to the second cycle. This is expected because the high-temperature pIRIR signals have more residual doses than the low temperature IRSL signals. This suggests that after the short solar simulator bleaching $(10 \mathrm{~min})$, the $110^{\circ} \mathrm{C}$ IRSL signals can be effectively bleached while a considerable amount of residual signals remained in high-temperature pIRIR signals. In contrast, all $\mathrm{T}_{\mathrm{x}}$ (dashed lines) increase with cycle number. The higher the stimulation temperature of pIRIR is, the smaller the sensitivity increases in repeated measurement cycles, indicating variation in sensitivity changes for pIRIR signals stimulated under different temperatures.

For WB, it is observed that $\mathrm{L}_{\mathrm{x}}$ (bold line) constantly increases with the stimulation temperature (Fig. 3b). The higher the stimulation temperature of pIRIR is, the less the sensitivity increases. $T_{x}$ shows a similar pattern as $L_{x}$. There is no systematic variation of $L_{x} / T_{x}$ with cycle number (Fig. 3b), indicating that the sensitivity change can be corrected for these samples. The results suggest that WB 

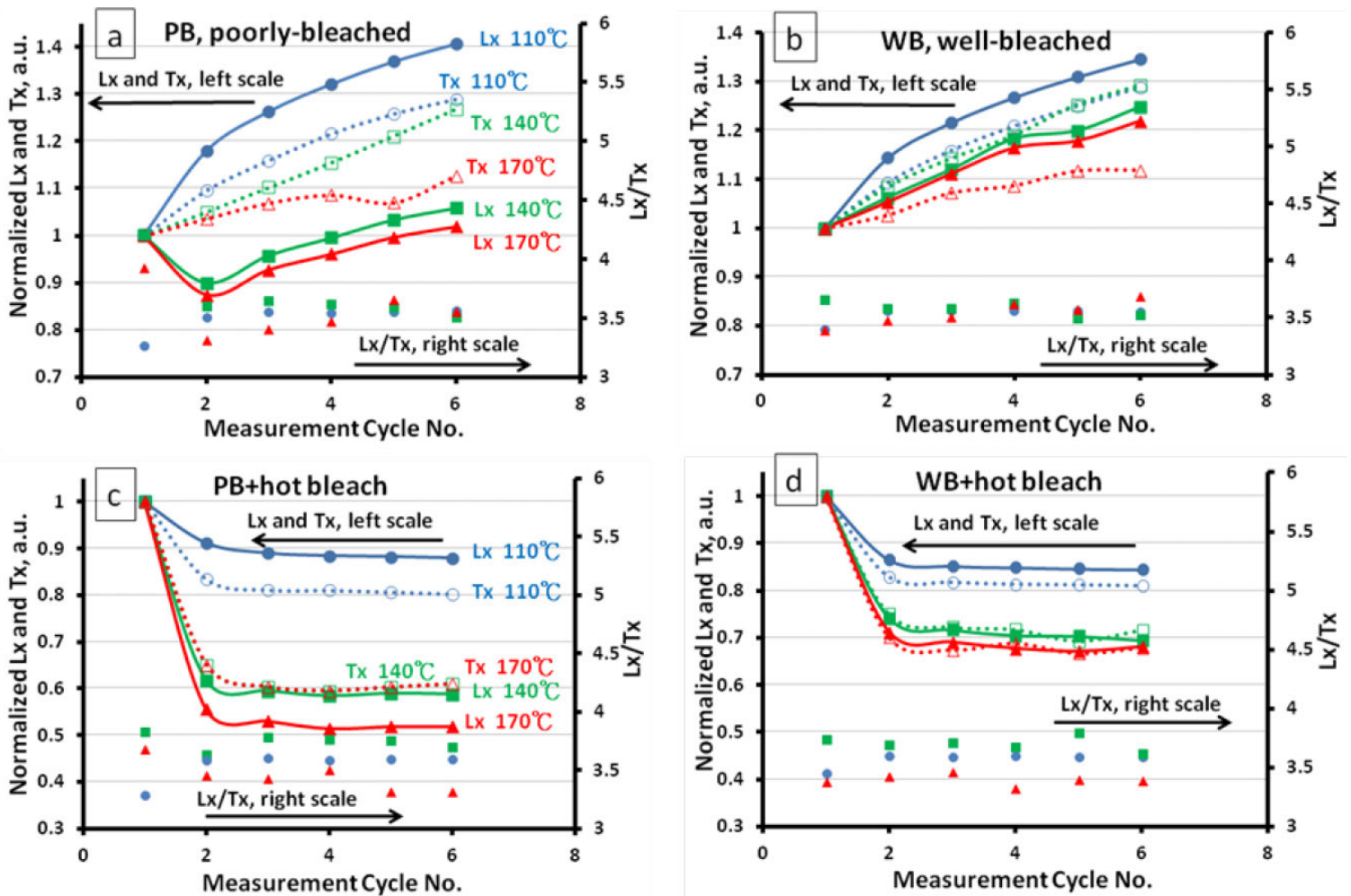

Fig. 3. To monitor sensitivity changes as function of measurement cycles, WB and $P B$ were given a constant dose of 25 Gy for $L_{x}$ measurement and $6.3 \mathrm{~Gy}$ for $T_{x}$ measurement, using the MET-pIRIR protocol (110, 140 and $170^{\circ} \mathrm{C}$ ), repeated for six cycles (Fu and Li, 2013). Details of the protocol are described in Table 3. Normalized $L_{x}$ (bold line, left scale), $T_{x}$ (dashed line, left scale) and $L_{x} / T_{x}$ ratio (points, right scale) changes with the measurement cycle numbers for MET-pIRIR protocol, at $110^{\circ} \mathrm{C}$ (blue), $140^{\circ} \mathrm{C}$ (green) and $170^{\circ} \mathrm{C}$ (red). Six aliquots were measured for WB and PB, respectively, and a hot bleach at the end of every measurement cycle (IRSL $280^{\circ} \mathrm{C}, 100 \mathrm{~s}$ ) was adopted to every three aliquots of the six. a) for poorlybleached sample PB; b) for well-bleached sample WB; c) for PB+hot bleach; d) for WB+hot bleach.

was well bleached and hence negligible residual signals present in the first $\mathrm{L}_{\mathrm{x}}$ measurement, even for the pIRIR $170^{\circ} \mathrm{C}$ signals.

Figs. $3 \mathbf{c}$ and $\mathbf{d}$ show the results with a hot bleach for PB and WB, respectively. Different patters from Figs. 3a and $\mathbf{b}$ were observed: both $\mathrm{L}_{\mathrm{x}}$ and $\mathrm{T}_{\mathrm{x}}$ decrease significantly from first cycle to the second cycle. They keep decreasing continuously in a smaller degree from the second to the third cycles. After the third cycle, the sensitivity generally remains unchanged. Larger decreases are observed for both $\mathrm{L}_{\mathrm{x}}$ and $\mathrm{T}_{\mathrm{x}}$ for pIRIR signals stimulated at high temperatures. These larger decreases are contributed from both residual and sensitivity decrease. As shown for the $\mathrm{L}_{\mathrm{x}} 140$ and $170^{\circ} \mathrm{C}$ of $\mathrm{PB}$ (Fig. 3a), an apparent drop is found from the first to the second cycle, but not in the $\mathrm{L}_{\mathrm{x}} 110^{\circ} \mathrm{C}$, suggesting that considerable amount of residual signal presented in the hightemperature pIRIR signals. However, $T_{x}$ increases with measurement cycle number in Figs. 3a and b, while decreases in Figs. 3c and d. Comparing with Fig. 3a, the extent of decrease for 140 and $170^{\circ} \mathrm{C} \mathrm{L}_{\mathrm{x}}$ in Fig. 3c is significantly larger after the hot bleach. It is thus suggested that the sensitivity for the pIRIR signals decreases after the hot bleach. WB also shows a similar decrease
(Fig. 3d). From the first cycle to the second, the extent of decrease for $T_{x}$ in Fig. 3d is smaller than that in the Fig. $3 c$, indicating that the sensitivity decrease is larger for $\mathrm{PB}$ than for WB after the hot bleach. Negligible difference for sensitivity decrease is observed between PB and WB after the first cycle, suggesting that the sensitivity decrease mainly occurs in the initial measurement cycles, especially between the first and the second cycles. Sensitivity change from the measurement of natural signal to immediately following $T_{x}$ measurement has also been reported for quartz OSL signals (Singhvi et al., 2011).

\section{MET-pIRIR protocol $\left(50,100,150,200,250^{\circ} \mathrm{C}\right)$}

The $50^{\circ} \mathrm{C}$ interval MET-pIRIR protocol $(\mathrm{Li}$ and $\mathrm{Li}$, 2011), was tested using both WB and PB. Figs. $4 \mathbf{a}$ and $\mathbf{b}$ show the results for $\mathrm{PB}$ and $\mathrm{WB}$ without a hot bleach, respectively. Similar to Fig. $3 a$, both $L_{x}$ and $T_{x}$ of $P B$ show a general increasing trend between the first and the second cycles for low-temperature pIRIR signals (Fig. 4a). However, in contrast to Fig. 3a high-temperature pIRIR signals decrease with the cycles (Fig. 4a). As discussed above, the residual signal is one of reasons accounting for the $\mathrm{L}_{\mathrm{x}}$ decrease between the first cycle and the second cycle. For the $T_{x}$ signals at high temperatures, 

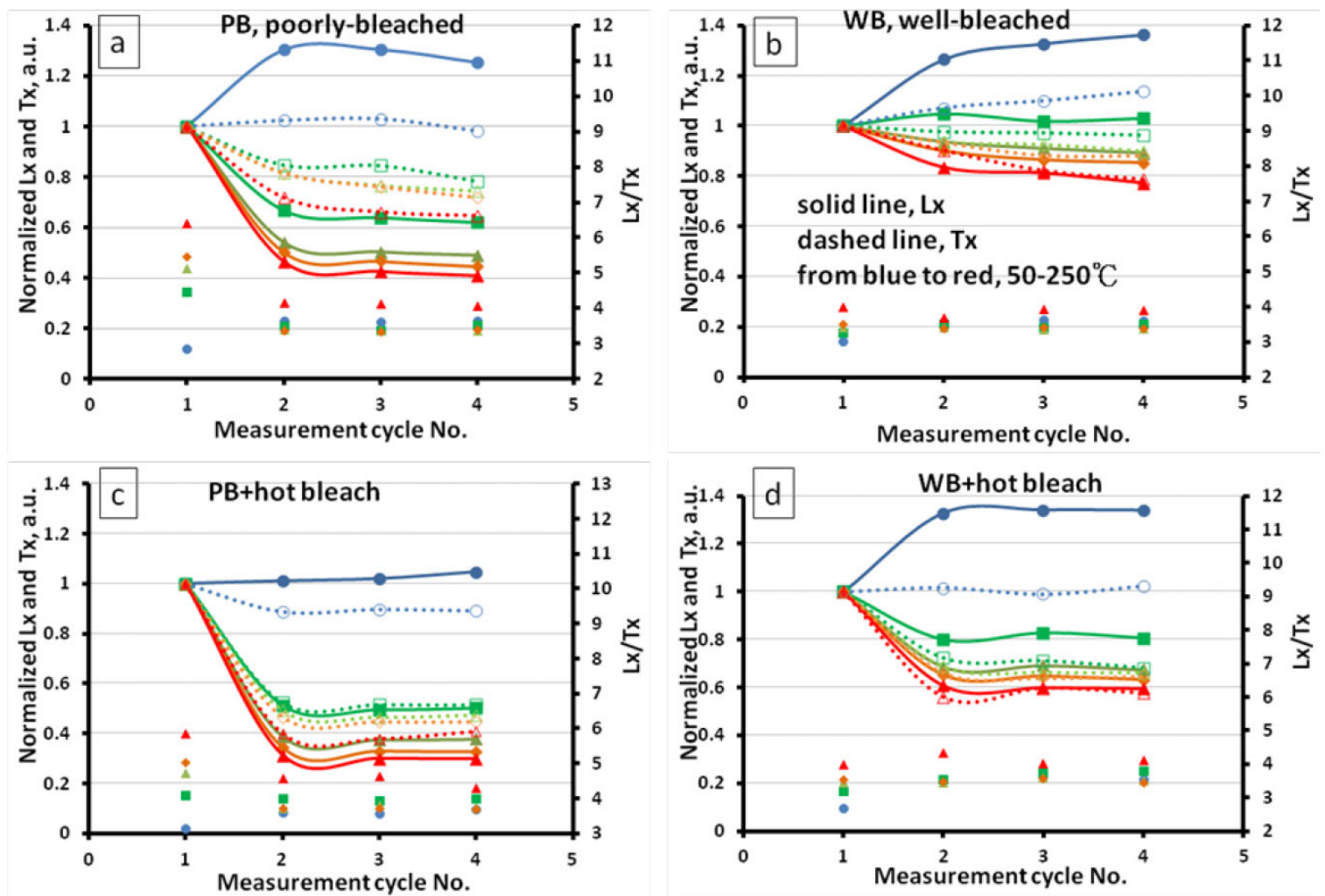

Fig. 4. Sensitivity changes of WB and PB as function of measurement cycles (a constant dose of $25 \mathrm{~Gy}$ for $L_{x}$ measurement and $6.3 \mathrm{~Gy}$ for $T_{x}$ measurement), using the MET-pIRIR protocol (50,100,150,200, 250 ${ }^{\circ} \mathrm{C}$ ), repeated for four cycles (Li and Li, 2011). Six aliquots were measured for WB and $P B$, respectively, and a hot bleach at the end of every measurement cycle (IRSL $320^{\circ} \mathrm{C}, 100 \mathrm{~s}$ ) was adopted to every three of the six aliquots. Normalized $L_{x}$ (bold line), $T_{x}$ (dashed line) and $L_{x} / T_{x}$ ratio (points) changes with the measurement cycle numbers for MET-pIRIR protocol, at $50^{\circ} \mathrm{C}$ (blue), $100^{\circ} \mathrm{C}$ (green), $150^{\circ} \mathrm{C}$ (yellow-green), $200^{\circ} \mathrm{C}$ (yellow) and $250^{\circ} \mathrm{C}$ (red). a) for PB; b) for WB; c) for PB+hot bleach; d) for WB+hot bleach. The experimental conditions are shown in Table 3. Note that the figure contains many lines and using different colours would be easier to distinguish these IRSL signals stimulated at various temperatures.

they also decrease with cycles, suggesting that a sensitivity decrease has already occurred in the MET-pIRIR (50$250^{\circ} \mathrm{C}$ ) signals, even without the hot bleach. $\mathrm{T}_{\mathrm{x}}$ and $\mathrm{L}_{\mathrm{x}}$ for WB also show such decrease at temperatures above $150^{\circ} \mathrm{C}$ (Fig. 4b). Comparing with PB (Fig. 4a), the extent of decrease between the first and the second cycle is smaller for WB (Fig. 4b). This smaller extent of decrease for $T_{x}$ signals for WB suggests that sensitivity decrease is more severe for PB than WB. This behaviour was not observed in MET protocol of $\left(110,140,170^{\circ} \mathrm{C}\right)$ (Figs. 3a and $\mathbf{b})$. This can be explained as the highest stimulation temperature $\left(170^{\circ} \mathrm{C}\right)$ or the preheat $\left(200^{\circ} \mathrm{C}\right)$ in the MET $\left(110,140,170^{\circ} \mathrm{C}\right)$ is not high enough to induce this sensitivity changes. After adopting a hot bleach, sensitivity decrease is observed in Figs. 3c and d, suggesting that high-temperature preheat or pIRIR stimulation in the high temperatures of MET protocol $\left(50-250^{\circ} \mathrm{C}\right)$ plays a similar role to the hot bleach in terms of inducing the sensitivity changes.

The results suggest that sensitivity decrease could occur from $L_{x}$ to the immediately following $T_{x}$ measurement after conducting high-temperature treatment in the
pIRIR measurement. Since it is observed that sensitivity significantly decreases between the first and the second cycle, e.g. from $L_{1}$ to $L_{2}$ or from $T_{1}$ to $T_{2}$ (Figs. $3 c$ and d, and high temperature pIRIR signals in Figs. $4 \mathbf{a}$ and $\mathbf{b}$ ), if high temperature treatment is adopted in pIRIR protocols, it is reasonable to assume that the sensitivity decrease should be the largest between the measurement of $L_{n}$ and $\mathrm{T}_{\mathrm{n}}$ (or $\mathrm{L}_{1}$ and $\mathrm{T}_{1}$ in this study). In the following cycles, such decrease still presents but in a smaller degree. In this case, after adopting a high-temperature treatment in the pIRIR procedures, $T_{x}$ may not be successfully used to correct the sensitivity changes as the preceding hightemperature treatment could induce considerable sensitivity change for the $T_{x}$, especially in the first cycle measurement.

Figs. 4c and $d$ show the results with a hot bleach (IRSL $320^{\circ} \mathrm{C}, 100 \mathrm{~s}$ ) for PB and WB, respectively. Similar patterns to Figs. 3c and $\mathbf{d}$ are observed. The extent of sensitivity decrease is larger for high-temperature pIRIR signals, suggesting that sensitivity decrease is more severe for high-temperature pIRIR signals. The $T_{x}$ decrease is more severe for PB than WB (Fig. 4d), suggesting that 
PB has a larger sensitivity decrease after a hot bleach. The sensitivity correction (points in Fig. 4) also presents larger scatter, especially for the first measurement cycle. After the first cycle, negligible difference in sensitivity decrease is observed between WB and PB.

It has been reported that a high-temperature heat treatment (up to $600^{\circ} \mathrm{C}$ ) can reduce the IRSL sensitivity from K-feldspar (e.g. Richardson, 1994; Li et al., 2013b). In this study, sensitivity decrease is observed for METpIRIR signals for both WB and PB. It is found to be more severe in our poorly-bleached samples, suggesting that caution should be taken when dating poorly bleached sediments when high-temperature-treatment is adopted. It is noted that the sensitivity decrease mainly occurs in the initial measurement cycles, though our observation of sensitivity change is found from the $T_{x}$ signals between the first and the second cycles. Based on our observations, the sensitivity decrease mainly occurs in the initial measurement cycles. Hence it is interpreted as considerable sensitivity decrease between the measurement of $\mathrm{L}_{\mathrm{n}}$ and $T_{n}$ could happen after adopting a high-temperature treatment. The situation of sensitivity correction is more severe for PB as it shows larger sensitivity decrease compared with WB. It is thus suggested that caution should be exercised when using high-temperature treatment in these protocols. Sensitivity changes have been investigated during OSL measurement of natural signal in the quartz SAR procedure (e.g. Murray and Wintle, 2000), and it has been reported that sensitivity correction does not take into account the changes in sensitivity that could happen during the readout of the natural signal (Singhvi et al., 2011). It is noted that the luminescence mechanism for these two minerals is significantly different, but for reliable sensitivity correction to be met in the SAR protocol, possible sensitivity changes between $L_{n}$ and $T_{n}$ measurement must be carefully considered for both minerals.

\section{Sensitivity change in the two-step pIR-IRSL protocol}

Similar measurement was then carried out using the pIRIR $\left(50,225^{\circ} \mathrm{C}\right)$ and pIRIR $\left(50,290^{\circ} \mathrm{C}\right)$ protocols, for both WB and PB (Buylaert et al., 2009; Thiel, et al., 2011). The results are shown in Figs. 5 and 6. Similar behaviours in the MET-pIRIR results are observed. In the two step-pIRIR results, sensitivity also decreases after the hot bleach. The sensitivity decreases significantly from the first to the second cycle. If high temperature treatment is used in the pIRIR measurement, a large sensitivity decrease could occur between the $L_{n}$ measurement and the $T_{n}$ measurement following it. This could lead to prob-
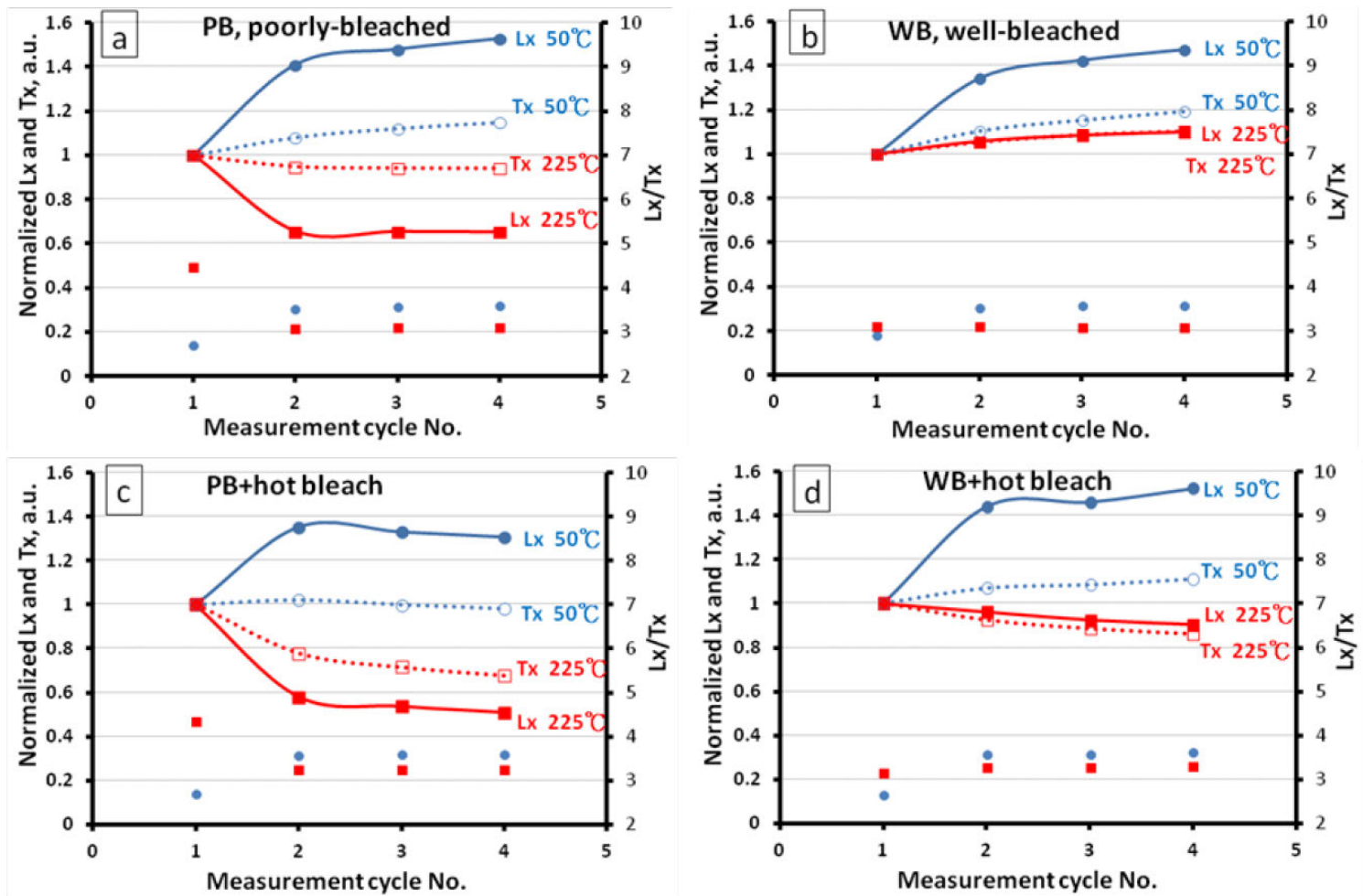

Fig. 5. Sensitivity changes of $W B$ and $P B$ as a function of measurement cycle number, using pIRIR $\left(50,225^{\circ} \mathrm{C}\right)$, repeated for four cycles (Buylaert et al., 2009). Six aliquots were measured for WB and PB, respectively, and a hot bleach at the end of every measurement cycle (IRSL $\left.290^{\circ} \mathrm{C}, 40 \mathrm{~s}\right)$ was applied to every three of the six aliquots. Normalized $L_{x}$ (bold line), $T_{x}$ (dashed line) and $L_{x} / T_{x}$ ratio (points) changes with the measurement cycle numbers for pIR-IRSL protocol, at $50^{\circ} \mathrm{C}$ (blue) and $225^{\circ} \mathrm{C}$ (red). a) for PB; b) for WB; c) for PB+hot bleach; d) for WB+hot bleach. Details of the protocol are shown in Table 3. 

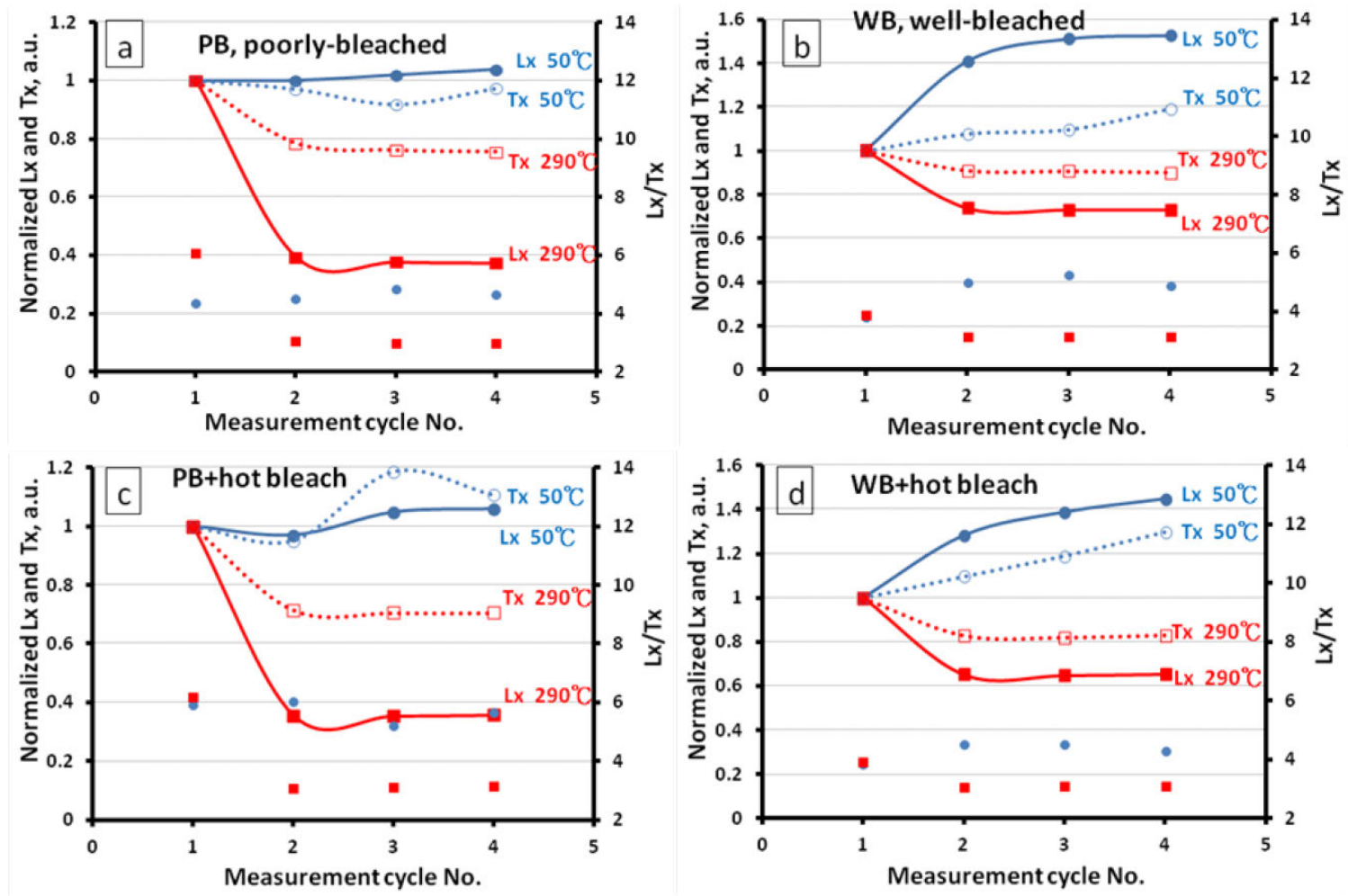

Fig. 6. Sensitivity changes of WB and PB as function of measurement cycles, using pIRIR $\left(50,290^{\circ} \mathrm{C}\right)$, repeated for four cycles (Thiel et al., 2011). Six aliquots were measured for WB and PB, respectively, and a hot bleach at the end of every measurement cycle (IRSL $\left.325^{\circ} \mathrm{C}, 100 \mathrm{~s}\right)$ was adopted to every three of the six aliquots. Normalized $L_{x}$ (bold line), $T_{x}$ (dashed line) and $L_{x} / T_{x}$ ratio (points) changes with the measurement cycle numbers for pIR-IRSL protocol, at $50^{\circ} \mathrm{C}$ (blue) and $290^{\circ} \mathrm{C}$ (red). a) for PB; b) for WB; c) for PB+hot bleach; d) for WB+hot bleach. Similar patterns to Fig. 4 can be observed. Details of the protocol are shown in Table 3.

lems in sensitivity correction as high-temperature treatment during the natural signal measurement could induce severe sensitivity decrease for its following $\mathrm{T}_{\mathrm{n}}$ signal. In this case, $\mathrm{T}_{\mathrm{n}}$ could not correctly reflect the sensitivity for $\mathrm{L}_{\mathrm{n}}$.

The problem of sensitivity change is more severe for the poorly-bleached sample, because it is found that the extent of sensitivity decrease is larger for PB than for WB. Our result also suggests that the sensitivity decrease is more severe for high-temperature pIRIR signals, as they show larger sensitivity decrease compared with the low-temperature pIRIR (Figs. $\mathbf{5 c}$ and $\mathbf{d}, \mathbf{6 c}$ and $\mathbf{d}$ ). In this case, larger sensitivity decrease between $L_{n}$ and $T_{n}$ measurement occurs and leads to a more severe problem for sensitivity correction. The result suggests that caution must be exercised when using high temperature treatment in these protocols, because the sensitivity decreases by the high temperature treatment and then the sensitivity correction may be problematic. A similar problem has been mentioned by Vasiliniuc et al. (2012), who suggested that the pIRIR $300^{\circ} \mathrm{C}$ signal appears to suffer from dose dependent initial sensitivity changes for their oldest samples. However, several recent works have reported pIRIR protocols generally give OSL ages in agreement with independent age controls (e.g. Buylaert et al., 2012), suggesting that sensitivity-corrections are generally satis- factory in these studies. This implies that sensitivitycorrection problem may not be a common phenomenon for all K-feldspar. Since our observation of sensitivity change is from the $T_{x}$ signals between different measurement cycles, we suggest that more attention should be paid to sensitivity changes in various pIRIR protocols, as reliable sensitivity correction is the basis for accurate $D_{e}$ measurements.

\section{CONCLUSION}

The residual doses for laboratory simulated well- and poorly- bleached samples (WB and $\mathrm{PB}$ ) were measured using the two-step pIR-IRSL protocols of $\left(50,225^{\circ} \mathrm{C}\right)$, $\left(50,290^{\circ} \mathrm{C}\right)$ and $\left(200,290^{\circ} \mathrm{C}\right)$, and MET-pIRIR protocol $\left(50,100,150,200,250,300^{\circ} \mathrm{C}\right)$. The residual doses range from 2.2 to 49.0 Gy for PB and 0.6 to 20.4 Gy for WB. The results suggest that $\mathrm{PB}$ has larger residual dose than $\mathrm{WB}$, especially for the high-temperature pIRIR signals. The $D_{\mathrm{e}}-\mathrm{t}$ plots reach plateaus for the high-temperature pIRIR signals, for both the pIR-IRSL and MET-pIRIR protocols.

Sensitivity change as a function of measurement cycles for WB and $\mathrm{PB}$ were investigated using the two-step pIRIR protocols of $\left(50,225^{\circ} \mathrm{C}\right)$ and $\left(50,290^{\circ} \mathrm{C}\right)$, and 
MET-pIRIR protocols of $\left(50,100,150,200,250^{\circ} \mathrm{C}\right)$ and $\left(110,140,170^{\circ} \mathrm{C}\right)$. Sensitivity decrease is observed after a high-temperature treatment is adopted, especially between the first and second cycles. This decrease is more severe for PB and more severe for the high-temperature pIRIR signals. Our result suggests that sensitivity correction could be problematic and special attention should be paid to sensitivity correction when using high temperature treatment in these protocols.

\section{ACKNOWLEDGEMENTS}

Dr. Tony Reimann and another anonymous reviewer are appreciated for their constructive comments and detailed recommendations. This study was financially supported by the grants to Sheng-Hua Li from the Research Grant Council of the Hong Kong Special Administrative Region, China (Project no. 7028/08P and 7033/12P).

\section{REFERENCES}

Aitken MJ, 1998. An Introduction to Optical Dating. Oxford, Oxford University Press: $359 \mathrm{pp}$

Bøtter-Jensen L, Bulur E, Duller GAT and Murray AS, 2000. Advances in luminescence instrument systems. Radiation Measurements 32(5-6): 523-528, DOI 10.1016/S1350-4487(00)00039-1.

Buylaert JP, Murray AS, Thomsen KJ and Jain M, 2009. Testing the potential of an elevated temperature IRSL signal from K-feldspar. Radiation Measurements 44(5-6): 560-565, DOI 10.1016/j.radmeas.2009.02.007.

Buylaert JP, Jain M, Murray AS, Thomsen KJ, Thiel C and Sohbati R, 2012. A robust feldspar luminescence dating method for Middle and Late Pleistocene sediments. Boreas 41(3): 435-451, DOI 10.1111/j.1502-3885.2012.00248.x.

Fu X, Li B and Li SH, 2012. Testing a multi-step post-IR IRSL dating method using polymineral fine grains from Chinese loess. Quaternary Geochronology 10: 8-15, DOI 10.1016/j.quageo.2011.12.004.

$\mathrm{Fu} \mathrm{X}$ and $\mathrm{Li} \mathrm{SH}, 2013$. A modified multi-elevated-temperature post-IR IRSL protocol for dating of Holocene sediments using K-feldspar. Quaternary Geochronology 17: 44-54, DOI 10.1016/j.quageo.2013.02.004.

Huntley DJ and Lamothe M, 2001. Ubiquity of anomalous fading in Kfeldspars and the measurement and correction for it in optical dating. Canadian Journal of Earth Sciences 38(7): 1093-1106, DOI 10.1139/cjes-38-7-1093

Li B and Li SH, 2011. Luminescence dating of K-feldspar from sediments: A protocol without anomalous fading correction. Quater$\begin{array}{llll}\text { nary Geochronology 6(5): } & 468-479, & \text { DOI }\end{array}$ 10.1016/j.quageo.2011.05.001.

Li B and Li SH, 2012a. A reply to the comments by Thomsen et al. on "Luminescence dating of K-feldspar from sediments: A protocol without anomalous fading correction". Quaternary Geochronology 8: 49-51, DOI 10.1016/j.quageo.2011.10.001.

Li B and Li SH, 2012b. Luminescence dating of Chinese loess beyond 130 ka using the non-fading signal from K-feldspar. Quaternary Geochronology 10: 24-31, DOI 10.1016/j.quageo.2011.12.005.

Li B, Robert RG and Jacobs Z, 2013a. On the dose dependency of the bleachable and non-bleachable components of IRSL from Kfeldspar: improved procedures for luminescence dating of Quater nary sediments. Quaternary Geochronology 17: 1-13, DOI 10.1016/j.quageo.2013.03.006.

Li B, Robert RG, Jacobs Z and Li SH, 2013b. Extending the age limit of luminescence dating using the dose-dependent sensitivity of METpIRIR signals from K-feldspar. Quaternary Geochronology 17: 55-67, DOI 10.1016/j.quageo.2013.02.003.

Li SH and Wintle AG, 1992. Luminescence sensitivity changes due to bleaching of sediments. Nuclear Tracks and Radiation Measurements 20(4): 567-573, DOI 10.1016/1359-0189(92)90006-H.

Madsen AT, Buylaert JP and Murray AS, 2011. Luminescence dating of young coastal deposits from New Zealand using feldspar. Geochronometria 38(4): 378-390, DOI 10.2478/s13386-011-0042-5.

Murray AS and Wintle AG, 2000. Luminescence dating of quartz using an improved single-aliquot regenerative-dose protocol. Radiation Measurements 32(1): 57-73, DOI 10.1016/S1350-4487(99)00253-

Reimann T, Tsukamoto S, Naumann M and Frechen M, 2011. The potential of using K-rick feldspars for optical dating of young coastal sediments-A test case from Darss-Zingst peninsula (southern Baltic Sea coast). Quaternary Geochronology 6: 207-222, DOI 10.1016/j.quageo.2010.10.001

Reimann T, Thomsen KJ, Jain M, Murray AS and Frechen M, 2012. Single-grain dating of young sediments using the pIRIR signal from feldspar. Quaternary Geochronology 11: 28-41, DOI 10.1016/j.quageo.2012.04.016.

Reimann T and Tsukamoto S, 2012. Dating the recent past $(<500$ years) by post-IR IRSL feldspar - Examples from the North Sea and Baltic Sea coast. Quaternary Geochronology 10: 180-187, DOI 10.1016/j.quageo.2012.04.016.

Richardson CA, 1994. Effects of bleaching on the sensitivity to dose of the infrared stimulated luminescence of potassium-rich feldspars from Ynyslas, Wales. Radiation Measurements 23(2-3): 587-591, DOI 10.1016/1350-4487(94)90104-X.

Singhvi AK, Stokes SC, Chauhan N, Nagar YC and Jaiswal MK, 2011. Changes in natural OSL sensitivity during single aliquot regeneration procedure and their implications for equivalent dose determination. Geochronometria 38(3): 231-241, DOI 10.2478/s13386011-0028-3.

Spooner NA, 1994. The anomalous fading of infrared-stimulated luminescence from feldspars. Radiation Measurements 23(2-3): 625632, DOI 10.1016/1350-4487(94)90111-2.

Thiel C, Buylaert JP, Murray AS, Terhorst B, Hofer I, Tsukamoto S and Frechen M, 2011. Luminescence dating of the Stratzing loess profile (Austria) - Testing the potential of an elevated temperature post-IR IRSL protocol. Quaternary International 234(1-2): 23-31, DOI 10.1016/j.quaint.2010.05.018.

Thomsen KJ, Murray AS, Jain M and Bøtter-Jensen L, 2008. Laboratory fading rates of various luminescence signals from feldspar-rich sediment extracts. Radiation Measurements 43(9-10): 1474-1486, DOI 10.1016/j.radmeas.2008.06.002.

Vasiliniuc S, Vandenberghe DAG, Timar-Gabor A, Panaiotu C, Cosma C and van den Haute P, 2012. Testing the potential of elevated temperature post-IR IRSL signals for dating Romanian loess. Quaternary Geochronology 10: 75-80, DOI 10.1016/j.quageo.2012.02.014.

Wallinga J, Murray AS and Wintle AG, 2000. The single-aliquot regenerative-dose (SAR) protocol applied to coarse-grain feldspar. $R a-$ diation Measurements 32(5-6): 529-533, DOI 10.1016/S13504487(00)00091-3.

Wintle AG, 1973. Anomalous fading of thermoluminescence in mineral samples. Nature 245: 143-144, DOI 10.1038/245143a0.

Wintle AG and Murray AS, 2006. A review of quartz optically stimulated luminescence characteristics and their relevance in single aliquot regeneration dating protocols. Radiation Measurements 41(4): 369-391, DOI 10.1016/j.radmeas.2005.11.001. 